Revista de la red interuniversitaria de estudios sobre las literaturas rioplatenses contemporáneas en Francia

\title{
De Escalot a Shalott : la damisela en su trama
}

\section{Susana G. Artal}

\section{OpenEdition}

\section{Journals}

Edición electrónica

URL: http://journals.openedition.org/lirico/1192

DOI: 10.4000/lirico.1192

ISSN: 2262-8339

Editor

Réseau interuniversitaire d'étude des littératures contemporaines du Río de la Plata

Referencia electrónica

Susana G. Artal, « De Escalot a Shalott : la damisela en su trama », Cuadernos LIRICO [En línea],

9 | 2013, Puesto en línea el 01 septiembre 2013, consultado el 30 abril 2019. URL : http:// journals.openedition.org/lirico/1192; DOI : 10.4000/lirico.1192

Este documento fue generado automáticamente el 30 abril 2019.

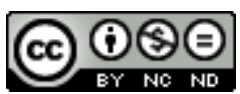

Cuadernos LIRICO está distribuido bajo una Licencia Creative Commons Atribución-NoComercialSinDerivar 4.0 Internacional. 


\title{
De Escalot a Shalott : la damisela en su trama
}

\author{
Susana G. Artal
}

Inserta en La Mort le roi Artu ${ }^{1}$, roman anónimo del siglo XIII que constituye la tercera y última parte del Lancelot en prosa ${ }^{2}$, la trágica historia de la demoiselle d'Escalot ha demostrado una extraordinaria vitalidad. Durante el medioevo, el personaje reapareció tanto en reescrituras cíclicas como no cíclicas, en una diversidad de lenguas (alemán, holandés, inglés, italiano, catalán e incluso, fragmentariamente, en un roman artúrico hebreo), que evidencia el enorme impacto del ciclo Lancelot-Grial (Le Lan 2005 : capítulo 10). Luego de eclipsarse entre los siglos XVI y XVIII, el renacimiento artúrico en la Inglaterra victoriana rescató a la última enamorada de Lancelot, en particular a través de la poesía de Lord Alfred Tennyson y de la vasta iconografía de que la dotó el interés de los pintores prerrafaelistas (en especial, Dante Gabriel Rossetti y William Holman Hunt), que se prolongó en obras de otros artistas más o menos vinculados a ese grupo (entre ellos, el autor de la más famosa de las representaciones pictóricas de la doncella, John William Waterhouse $)^{3}$ y en el trabajo de ilustradores de la talla de Gustave Doré y Howard Pyle.

2 Nuestra doncella, que también irrumpió en los escenarios de ópera ${ }^{4}$, reapareció en el siglo XX no solo en las adaptaciones del Lancelot-Grial, sino también en obras teatrales ${ }^{5}$, en el entramado de novelas anglófonas, e incluso en los terrenos de las paraliteraturas. ${ }^{6}$ De tan vasto conjunto, por cierto inabarcable en los límites de este trabajo, me propongo retomar aquí tan solo ciertos elementos que creo especialmente significativos para reexaminar el episodio no desde la perspectiva de la infortunada historia de amor, sino en lo que apunta al riesgoso equilibrio entre la realidad, la fantasía, la creación y el arte. Para eso, tendré en cuenta el episodio del roman francés del siglo XIII, la novella LXXXII del Novellino, el poema «The Lady of Shalott » de Tennyson y las representaciones plásticas de William Holman Hunt. 


\section{La historia de la demoiselle en La Mort le roi Artu}

Desde el estudio pionero sobre la Mort de Jean Frappier (1936 : 267-273) hasta la brillante tesis de Nadège Le Lan (2005), las cinco secuencias que conforman en el roman francés el drama de la desdichada doncella han sido examinadas una y otra vez por la crítica. La historia puede resumirse en algunas líneas. En camino hacia el torneo de Winchester, Lancelot, que ha partido de incógnito, se aloja en el castillo de un valvasor, cuya hija consigue que le conceda el don de llevar su manga en el torneo. Mientras Lancelot, malherido pese a haber triunfado, se recupera en la morada de una tía de la joven, Gauvain, que ha salido en busca del vencedor de la justa, cuya identidad ignora, llega a Escalot e intenta en vano seducir a la muchacha, que le anuncia que ama a otro mejor que él. Intrigado y herido en su orgullo, el sobrino de Arturo insiste en saber quién ha sido preferido por sobre él y ella le muestra el escudo de Lancelot, con lo que Gauvain descubre la identidad del caballero que buscaba y deduce que la ausencia de Lancelot se debe a que ama a la bella damisela, novedad que no tarda en relatar en cuanto regresa a la corte, con lo que provoca los celos de Guenièvre al mismo tiempo que disipa las dudas de Arturo acerca de la conducta de Lancelot y la reina. Entretanto, la joven llega a la casa de su tía y su pasión por Lancelot se vuelve cada día más intensa hasta llevarla a confesarle su amor, ante lo cual él le deja claro que ama a otra y ella anuncia que morirá en consecuencia. Al marcharse el caballero, la demoiselle se acuesta y no deja el lecho hasta morir. Tiempo después, una nave llega a Camelot con el cuerpo de la muchacha y una carta, en la que ella anuncia quién es y por qué ha muerto.

En la Mort, el episodio de la doncella de Escalot no es un bloque continuo (como ocurre, por ejemplo, en la versión de Malory) ${ }^{7}$ sino que se inserta mediante la técnica del entrelazamiento. Dividida en cinco etapas, cada una de las cuales tiene sus repercusiones en el desarrollo general de la trama, la historia de la joven, al dilatar y retrasar la resolución del conflicto planteado al principio del roman (es decir, el descubrimiento del adulterio de la reina), no solo incrementa el dramatismo del conjunto sino que contribuye a revelar facetas e intereses ocultos. Tanto cuando dan pie a malentendidos como cuando por el contrario los despejan, los actos de la hija del valvasor tienen consecuencias cruciales que ella jamás alcanza siquiera a atisbar, ya que escapan por completo a los límites de su experiencia. La llegada de la barca funeraria y la lectura de la carta, por fin, al desmentir la interpretación de Gauvain, cierran las ilusiones de Arturo acerca de la conducta de Lancelot y Guenièvre, restauran la concordia entre los amantes y abren la puerta a la crisis que desencadenará la caída del reino.

\section{Entre la demoiselle y la lady, una damigella}

5 Aunque entre el roman francés y el poema "The Lady of Shalott» de Lord Alfred Tennyson media una extensa trayectoria de reescrituras y recreaciones, en el momento en que lo concibió, el poeta inglés solo parece haber conocido una : la novella LXXXII de la colección Cento Novelle Antiche (1281-1300), también llamada Il Novellino. ${ }^{8}$ Pese a su brevedad, como señala Nadège Le Lan (250), el texto italiano, cuya fuente es el roman francés ${ }^{9}$, tiene una gran importancia en la transmisión de la historia de la desafortunada doncella, por un lado, por ser el único texto medieval en que esa historia se presenta de modo absolutamente autónomo ; por otro, por ser la fuente de las primeras reescrituras

Cuadernos LIRICO, 9 | 2013 
modernas. La novella prescinde no solo de los acontecimientos que rodean el episodio y la repercusión de éste en la trama de La Mort le roi Artu, sino también de todas las circunstancias del enamoramiento, para concentrarse exclusivamente en las disposiciones fúnebres que toma la enamorada, la llegada de la nave y la lectura de la carta. $^{10}$

6 En el marco de este proceso de síntesis extrema, llama la atención el hecho de que el texto italiano amplifique notablemente un elemento: la descripción de cómo deben engalanarse el cuerpo y la nave. ${ }^{11}$ Mientras que el roman francés se limita a señalar que la barca, cubierta de telas de seda, era bella, rica y estaba elegantemente dispuesta, y el lecho estaba provisto " de todas las bellas cosas con que un rico lecho puede proveerse $»^{12}$ , la novella detalla el color de las telas, menciona que el lecho debe estar ornado de piedras preciosas y llevar sábanas de seda, insiste en el atavío de la doncella, la corona que debe portar, el cinturón con la limosnera :

[...] commandò [...] che fosse arredata una ricca navicella coperta d'uno vermiglio sciamito, con uno ricco letto iv'entro con ricche e nobile coverture di seta, ornato di ricche pietre preziose : e fosse il suo corpo messo in su questo letto, vestita di suoi piue nobili vestimenti e con bella corona in capo, ricca di molto oro e di molte care pietre, e con ricca cintura e borsa ; e in quella borsa avea una lettera, che era dello 'nfrascritto tenore. (CNA, 317)

7 Le Lan ve en esta amplificación un rasgo que atenta contra la dimensión trágica del episodio: "Coupé du contexte, donc potentiellement révélateur de la puissance dramatique de l'événement, le conte amoindrit pourtant la dimension tragique de l'épisode en n'insistant que sur le faste » (250), conclusión con la que disiento.

En mi opinión, lo más notable de este desarrollo del texto italiano no es en modo alguno la insistencia en lo suntuoso sino el hecho de que, a diferencia del roman francés, en el que la preparación de la nave y la carta está por completo silenciada (en realidad, no se dice quién decide embarcar el cuerpo ni quién escribe la misiva, solo podemos suponerlo), en la novella todas las disposiciones se atribuyen explícitamente a la propia doncella, a quien, de este modo, se le asigna por primera vez una posición activa en la organización de su último viaje. ${ }^{13}$ Paralelamente, como señala Segre $(1974: 85)$, las múltiples referencias a la belleza de la muchacha, que en el roman francés sin duda encarecen la fidelidad de Lancelot, se ven desplazadas por la descripción de la nave y los vestidos. ${ }^{14}$ Pero este cambio no solo implica una focalización diferente, que coloca a la damigella en el centro absoluto de una escena en la que solo cuenta su amor desgraciado (y ya no más el conflicto de Lancelot), sino que confluye con la intención de poner en valor las decisiones de la doncella.

9 El interés de la novella por mostrar a la protagonista montando lo que podríamos denominar una escenografía de su propia muerte se enlaza, por un lado, con la tendencia fantasiosa que manifiesta el personaje del roman francés, quien, a partir de un gesto de Lancelot (haber llevado en el torneo la manga), obtenido por el respeto de una convención cortesana (la costumbre del don contraignant) ${ }^{15}$, forja, casi como una Emma Bovary avant la lettre, una historia de amor que recuerda quizá el principio de la de Enide en el roman de Chrétien ${ }^{16}$, pero que poco condice con el clima adusto de La Mort le roi Artu. La damigella de la versión italiana, concentrada en crear una verdadera puesta en escena de su propia muerte, tiende un puente entre la fantasía y el arte que, como veremos, juega un papel esencial en el poema de Tennyson. 


\section{La dama y su magic web}

10 La relación entre «The Lady of Shalott » y la novella fue muy pronto establecida. L. S. Potwin (1902: 473-474), que escribe uno de los primeros artículos al respecto, reproduce el texto italiano con una traducción al inglés, observa que el dato fue señalado por el profesor Palgrave en nota a una edición del poema de 1885 y retomado por otros comentaristas, como Luce y J. Churton Collins, e invoca el testimonio de Hallam Tennyson, hijo y biógrafo del poeta. ${ }^{17} \mathrm{El}$ propio Alfred Tennyson escribió : «I met the story first in some italian novelle $\left[\right.$ sic] : but the web, mirror, island, etc. were my own ${ }^{18}{ }^{18}$

11 En efecto, a la base que le proporcionó la novella, que como vimos ya había operado un recorte sustancial del episodio narrado en el roman francés, Tennyson le agregó múltiples elementos. Aislada en una isla y sometida a una misteriosa maldición que le impide mirar o conectarse de modo directo con el mundo exterior, la dama de Shalott pasa días y noches tejiendo una tela mágica en la que representa las imágenes que ve reflejadas en su espejo, hasta el momento en que Lancelot cruza a caballo el campo lindero. El canto del caballero o quizás el resplandor de su armadura atraen a la muchacha que deja el telar y mira por la ventana. Entonces, el espejo se quiebra y ella comprende que el maleficio se ha cumplido ${ }^{19}$; baja de su torre, se tiende en una barca donde canta su última canción y deja que la corriente la lleve hasta llegar, ya muerta, a Camelot.

Las diferencias argumentales con respecto al episodio del roman francés son evidentes: además de todo lo que había desaparecido en la novella italiana, el poema de Tennyson suprime lo que parecía imposible eliminar : el fatal amor de la joven por Lancelot, con quien no existe contacto alguno. ${ }^{20}$ Por todo ello, Le Lan afirma que "The Lady of Shalott " marca « une rupture importante dans la généalogie » (274) y decide no realizar un estudio comparativo detallado de ese poema, como sí hace de «Lancelot and Elaine », uno de los Idilios del Rey (1859) en el que Tennyson vuelve a la historia de la doncella, esta vez enriquecida por la lectura de otras fuentes. ${ }^{21}$

No obstante, más allá de las diferencias evidentes, creo que, en un nivel más profundo, la dama de Shalott se integra a la perfección en el linaje de la demoiselle d'Escalot, y que el vínculo entre ambas es justamente uno de los elementos en apariencia más ajenos a la tradición medieval del personaje : me refiero específicamente a la magic web. En la figura de la joven que pasa noche y día trabajando con su telar la crítica ha reconocido una metáfora de la actividad del artista, que crea apartado del mundo que lo rodea, en el incierto, anegadizo límite entre la protección y la exclusión. La demoiselle de La Mort le roi Artu, que tramó la historia de un amor predestinado e insuperable a partir de un gesto de Lancelot; la damigella de la novella italiana, que como un director teatral ordena los detalles que transforman la llegada de su cadáver en un espectáculo que maravilla a la corte, y la lady del poema inglés, que convierte en coloridas imágenes las sombras que atisba en su espejo, comparten la misma capacidad de transmutar, crear, imaginar, cuyo alto riesgo muestran tanto el roman francés como el poema de Tennyson. En ambos casos corresponde a Lancelot, el mejor caballero del mundo, el ingrato papel de provocar involuntariamente la confrontación de las creaciones y la "realidad" del mundo externo, contacto fatal al que ni la lady ni la demoiselle sobreviven.

Resulta muy interesante al respecto observar las imágenes de la dama de Shalott hechas por William Holman Hunt. Como muchos otros artistas, Hunt eligió representar a la joven con su telar ${ }^{22}$ pero, a diferencia de la mayoría de sus colegas, que incluyeron en sus obras 
telares verticales ${ }^{23}$, él prefirió mostrarla con un telar circular o redondo. Esto no solo crea aproximaciones visuales sugestivas, por la similaridad de forma entre el espejo (es decir, la visión indirecta de la realidad que alimenta a la artista) y la tela (es decir, la creación en la que la artista transmuta esa visión) sino que además subraya el encierro del personaje, que aparece atrapado entre los hilos de su propia trama. Y valga aquí la conocida dilogia que nos permite pensar en tramas construidas con hilos y en tramas construidas con palabras. Esta idea de la dama enredada en los hilos de su magic web, que más tarde atrajo también a Waterhouse ${ }^{24}$, está presente desde los primeros acercamientos de Hunt al tema, como puede verse en el dibujo hecho en 1850 , y pese a las importantes diferencias que existen entre esa obra y las posteriores referidas al mismo personaje, se mantuvo tanto en la ilustración de Hunt para la célebre edición Moxon de los Poemas de Tennyson de 1857, como en la magnífica tela realizada entre 1886 y $1905 .{ }^{25}$
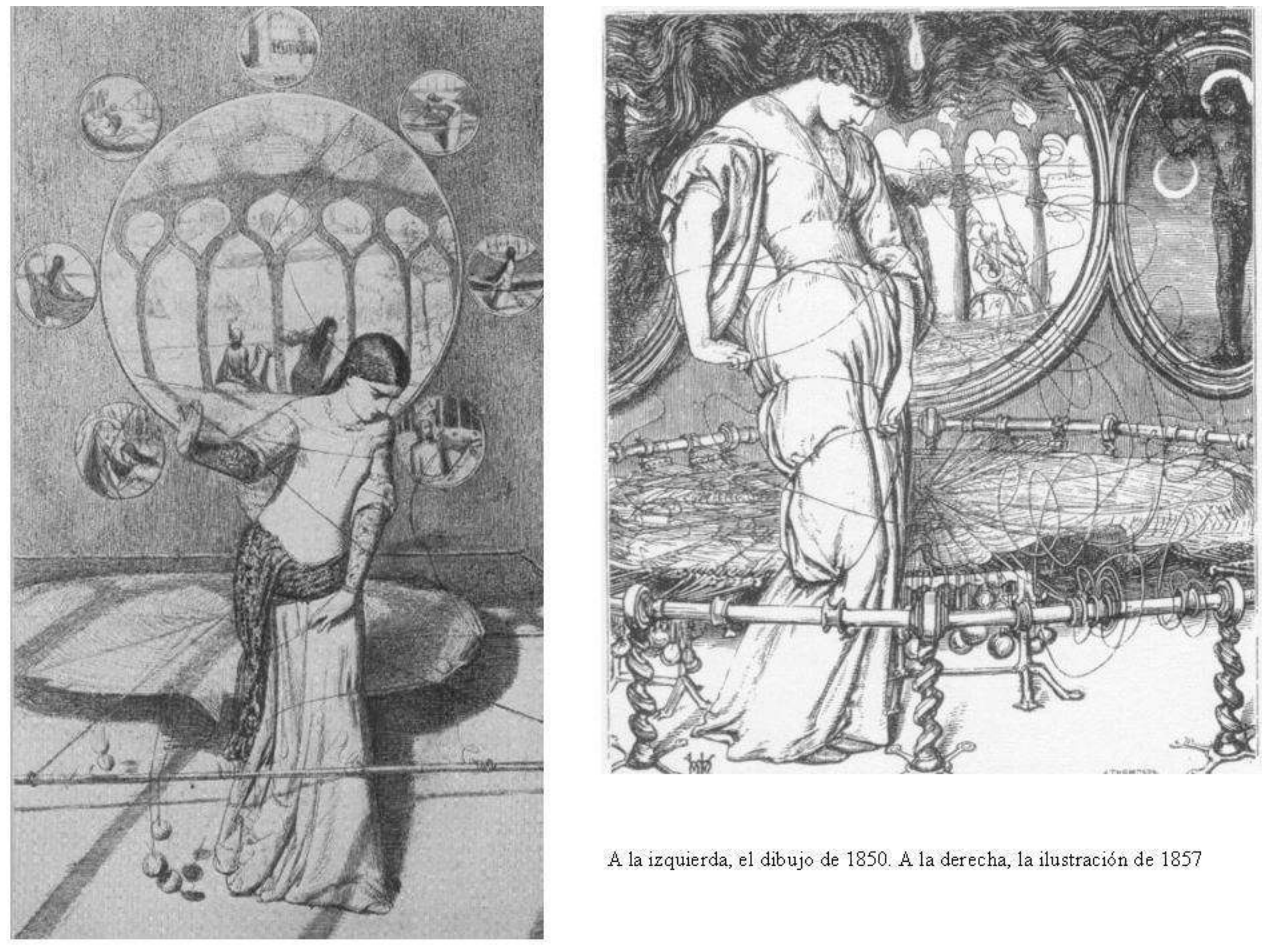

A la izquierda, el dibujo de 1850 . A la derecha, la ilustración de 1857

WILLIAM HOLMAN HUNT: THE LADY OF SHALOTT (1850 ET 1857)

Con razón se ha señalado que de la primera a la tercera de estas representaciones, el pintor fue acentuando, por un lado, la afirmación de la autonomía de su obra con respecto al poema (lo que provocó el disgusto de Tennyson) ${ }^{26}$, por otro, la intención de transmitir un mensaje moral : la doncella, que en el dibujo de 1850 inclina su rostro con mirada casta y rechaza con su mano la tentación, en la ilustración de 1857 ya muestra sus brazos desnudos, no ofrece resistencia y su cabellera, que se hará aún más exuberante en la última pintura, donde también se ven desnudos los pies y los tobillos, evidencia sensualidad. Paralelamente, Hunt multiplicó en torno a la figura la presencia de símbolos, que sustituyeron los círculos que, en el primer dibujo, rodean el espejo y permiten reconstruir las instancias argumentales del poema (ver Leng 1991).

El sentido de la enseñanza que el artista buscó impartir es claro: en la perspectiva de Hunt, la dama de Shalott es una más en las nutridas filas de las mujeres caídas, las que sucumbieron a la tentación que para la moral victoriana era, por supuesto, el sexo. Pero si contemplamos su tela superando esa óptica cuya validez, circunscripta a parámetros 
morales de época, ya están perimidos, reencontraremos de inmediato el hilo que, por debajo de la historia de amor, rastreamos en el complejo entramado del episodio de $L a$ Mort le roi Artu, en la novella LXXXII y en el poema de Tennyson: la reflexión sobre las fronteras riesgosas de la fantasía, el arte y la realidad.

\section{BIBLIOGRAFÍA}

\section{Obras literarias citadas}

La mort le roi Artu, roman du XIIIe siècle, ed. Jean Frappier. Paris : Droz, 1936.

La mort du roi Arthur, ed. David F. Hult. Paris : Le livre de Poche, Lettres Gothiques, 2009.

La mort du roi Arthur, ed. E. Baumgartner y M. T. de Medeiros. Paris : Honoré Champion, 2007.

La Muerte del rey Arturo. Trad. de Carlos Alvar. Madrid : Alianza Tres, 1980 y reeds.

Novellino. Le Cento Novelle Antiche. A cura di Guido Favati. Genova : Bozzi, 1970.

Lord Tennyson, Alfred. Poems of Alfred Lord Tennyson. Sel., introd., notas Charles Tennyson.

London and Glasgow : Collins, 1954.

\section{Bibliografía general}

Arnaud, Noël. "Boris Vian et l'opéra ", préface a : Boris Vian. Le chevalier de neige. Paris : Christian Bourgois, 1974, pp. 9-32.

Bolen, Anne. From Verse to Visual: An Analysis of Alfred Tennyson and William Holman Hunt's The Lady of Shalott. Tesis presentada en la Facultad del College of Fine Arts de Ohio University, 2004.

http://etd.ohiolink.edu/send-pdf.cgi/Bolen\%20Anne\%20E.pdf?ohiou1087832766

Cooper-Deniau, Corinne. « Culture cléricale et motif du 'don contraignant'« . En : Le Moyen Age, CXI, 2005 (9-39).

Frappier, Jean. Etude sur La Mort le roi Artu, roman du XIIIe siècle, dernière partie du Lancelot en prose. Paris : Droz, 1936.

Frappier, Jean. « Le motif du don contraignant dans la littérature du Moyen Age ». En : Travaux de Linguistique et de Littérature 7.2, 1969 (7-46). Reimpreso en su : Amour courtois et Table Ronde.

Genève, 1973, pp. 225-264.

Hult, David F. « Esquisses d'interprétation ». En : La mort du roi Arthur, ed. David F. Hult. Paris : Le livre de Poche, Lettres Gothiques, 2009, pp. 9-115.

Le Lan, Nadège. La demoiselle d'Escalot [1230-1978], morte d'amour, inter-dits, temps retrouvés. Paris : L'Harmattan, 2005.

Leng, Andrew. « The Ideology of 'eternal truth' : William Holman Hunt and the Lady of Shalott 1850-1905 ». En : Word \& Image 7, 1991 (314-328).

Menard, Ph. « Le don en blanc qui lie le donateur. Réflexions sur un motif de conte ». En : An Arthurian Tapestry. Essay in honor of Lewis Thorpe, Glasgow, 1981, pp. 37-53. 
Potwin, L. S. « The Source of Tennyson's The Lady of Shalott ». En : Modern Language Notes, XVII.8, 1902 (473-477).

Saad Hossne, Andrea. « Barcos à Deriva. 'Lady of Shalott' na Literatura e na Pintura ». En : Alea. Estudos Neolatinos, 4, 2002 (179-197).

Segre, Cesare. « Decostruzione e ricostruzione di un racconto (dalla Mort le roi Artu al Novellino)». En su : Le strutture e il tempo, Torino, Einaudi, 1974, pp. 79-86.

\section{NOTAS}

1. En adelante, puede designarse este roman como Mort o mediante la sigla MA. Toda cita corresponde a la edición de David Hult incluida en la sección de Obras citadas.

2. Este tríptico, que comprende además el Lancelot propio y La queste del Saint Graal, fue compuesto, según la mayoría de los especialistas, entre 1215 y 1230. Alexandre Micha propone un período más breve: 1225-1230 (Hult 2009: 13). Algunos años más tarde, a ese conjunto se sumaron L'Estoire del Saint Graal, L'Estoire de Merlin y la Suite Vulgata, que completan el extenso ciclo del Lancelot-Grial, de influencia decisiva en el desarrollo de la narrativa europea, que, según Jean Frappier, habría estado concluido hacia 1240.

3. Me refiero al óleo de 1888 de Waterhouse, que muestra a la doncella a punto de embarcarse y que se conserva en la Tate Britain, London. Este artista representó nuevamente a la doncella en 1894 (City Art Gallery, Leeds) y en la tela I am Half-Sick of Shadows, de 1916, actualmente en The Art Gallery of Ontario.

4. Nadège Le Lan (2005 : 322-339) ha señalado la existencia de tres óperas en el siglo XIX (Lancelot du Lac, de Augusta Holmes ; Elaine, de Herman Bemberg y Lancelot, de Victorin Joncières) y dos en el XX (The Lily Maid, de Rutland Boughton y Lanzelot and Elaine, de Walter Courvoisier).

5. Entre otras, Le chevalier de neige, de Boris Vian, que el autor luego reescribió como libreto para una ópera con música de Georges Delerue. Al respecto, véase Arnaud 1974.

6. Entre las novelas, Possession, de A. S. Byatt y Lady Oracle, de Margaret Atwood. En el campo de la literatura para niños, un ejemplo es el capítulo XXVIII de Ana de los Tejados Verdes, de la narradora canadiense Lucy M. Montgomery, y en el de la novela policial, El espejo se rajó de parte a parte de Agatha Christie. Véase Saad Hossne 2002.

7. En el roman francés, los cinco actos, como los llama Frappier, que constituyen la historia de la doncella corresponden a los $\S \S 13$ y $14 ; 25$ a $30 ; 38$ y 39; $57 ; 70$ a 73. En Le Morte Darthur de Malory, el episodio se desarrolla como un continuo, desde el capítulo IX hasta el XX del Libro XVIII.

8. En adelante, CNA. Según Le Lan, la novella LXXII es también la fuente de otros dos poemas referidos al mismo personaje y publicados antes que el de Tennyson: "The funeral Boat», de Louisa Stuart Costello (1829), y « A Legend of Tintagel Castle », de Letitia Elizabeth Landon (1832). 9. Como se desprende de la comparación del texto de la carta de la doncella en ambos textos (Le Lan 2005 : 252).

10. Segre (1974: 82-83) considera que los cambios introducidos por la novella provienen de necesidades estructurales derivadas del cambio genérico : « Tutti i cambiamenti apportati da $N$ [Il Novellino] derivano da una decisione abbastanza naturale : quella di spiegare ai lettori chi fosse la damigella d'Escalot. Il compilatore ha insomma compreso che per ottenere una novella doveva eliminari sí i riferimenti al romanzo per lui superflui, ma doveva inglobare per contro nel contesto gli elementi che nella MA lo preparano. »

11. La importancia de la amplificación queda clara si se tiene en cuenta que esa descripción ocupa casi la tercera parte de la extensión total de la novella. 
12. "si troverent enmi la nef .i. lit molt tres bien apareilliez de totes les beles choses dont nus riche liz poïst estre garniz » (MA, 406).

13. Una posición semejante adopta en Le Morte Darthur de Malory (1469), texto muy posterior a la novella italiana.

14. "Il tema della bellezza è un elemento importante nell'episodio della $M A$, in rapporto con la fedeltà adamantina di Lancilotto. $N$ [Novellino], attento solo a l'amore infelice della damigella, lo ha eliminato, rendendo invece, da accidentali che erano, funzionali, gli spunti (connotativi nella MA) sulla ricchezza degli addobbi e delle vesti. »

15. El don contraignant obliga a quien lo ha otorgado a conceder lo que se le solicite. Entre los numerosos trabajos que se han escrito acerca de este motivo en la literatura medieval, destaco los de J. Frappier 1969 ; Ph. Ménard 1981 ; Cooper-Deniau 2005.

16. Como nuestra demoiselle, Enide es la hermosísima hija de un valvasor (es decir, pertenece a la nobleza menor y, en el caso de Enide se insiste además en la pobreza de su familia), a cuya morada llega accidentalmente Erec, hijo del rey Lac y caballero de la corte artúrica, quien se enamora de inmediato y se casa con ella. La Mort Artu muestra dos contracaras trágicas de esa historia en el episodio de la demoiselle d'Escalot y el de la dama de Beloé (MA, 791-799).

17. "Through the kindness of the present Lord Tennyson I can said he believes Palgrave to be right » (Potwin, 1902 :474).

18. Rosetti Papers, 1862-1879, ed. por W. M. Rosetti. New York: Ch. Scribner's, 1903, p. 341. Citado por Le Lan, $2005: 274$, n. 377.

19. " From the bank and from the river/ He flash'd into the crystal mirror,/ 'Tirra lirra', by the river/ Sang Sir Lancelot.// She left the web, she left the loom,/ She made three paces through the room,/ She saw the water-lily bloom,/ She saw the helmet and the plume,/ She look'd down to Camelot./ Out flew the web and floated wide;/ The mirror crack'd from side to side :/ 'The curse is como upon me', cried/ The Lady of Shalott. "

20. Cuando Andrea Saad Hossne (2002 : 179) observa respecto al poema « Dos originais, apenas a desafortunada paixão não correspondida por sir Lancelot », probablemente confunde en este punto « The Lady of Shalott » con el idilio « Lancelot and Elaine ».

21. La crítica coincide en reconocer como fuente principal La muerte de Arturo de Malory. No obstante, Le Lan (299-303) sostiene la hipótesis de que ciertos detalles del idilio evidencian un conocimiento del roman francés, tal vez no directo, sino mediado por la traducción italiana: L'illustre et famosa historia di Lancilotto dal Lago.

22. Como observa Saad Hossne (2002: 180), «Para a representação pictórica, três momentos do poema são privilegiados : a figura da donzela tecelã ; o momento em que a maldição é deflagrada e o espelho encantado se quebra ; a donzela, viva o já morta, num barco à deriva ».

23. Por ejemplo, entre los pintores, Elizabeth Siddal, Waterhouse, Sydney Meteyard, Maw Egley. Entre los ilustradores, Howard Pyle, Frances Brundage.

24. Véanse sus telas de 1894 y 1916.

25. En realidad, se trata de dos óleos muy semejantes: uno se conserva en The Wadsworth Atheneum (Connecticut) y el otro en The Manchester Art Gallery.

26. En su libro Pre-Raphaelitism and the Pre-Raphaelite Brotherhood, Hunt "reconstruye" un diálogo en que Tennyson cuestiona tanto la cabellera « como un tornado » de la ilustración de 1857 como el hecho de que la tela rodee a la dama « like the threads of a cocoon ». La respuesta de Hunt no solo marca la diferencia entre dos lenguajes artísticos ( I had only half a page on which to convey the impression of weird fate, whereas you had about fifteen pages to give expression to the complete idea ») sino que busca rebatir la supuesta superioridad de la poesía sobre las artes plásticas y reivindicar la legitimidad de que su obra sea una representación artística autónoma. En otros términos, haberse tomado con respecto a su fuente una libertad comparable a la que el propio Tennyson se concedió respecto a las suyas. Al respecto, véanse Leng 1991 y Bolen 2004. 


\section{RESÚMENES}

La historia de la demoiselle d'Escalot, personaje secundario de La Mort le roi Artu, roman del siglo XIII que cierra el ciclo Lancelot-Graal, ha demostrado una extraordinaria vitalidad. Retomada en diversos textos medievales posteriores y rescatada en el siglo XIX por el revival de la materia artúrica en la Inglaterra victoriana, la última enamorada de Lancelot reaparece en el siglo XX en el entramado de novelas anglófonas, en obras teatrales e incluso en los terrenos de las paraliteraturas. Aunque el poema "The Lady of Shalott" de Lord Alfred Tennyson se ha visto como una ruptura en esa tradición, la comparación de esa poesía con su fuente directa, la novella 82 de Cento Novelle Antiche, y el roman francés permite reconstruir una línea temática que relaciona los tres textos.

L'histoire de la demoiselle d'Escalot, personnage secondaire de La Mort le roi Artu, roman du XIII siècle qui clôt le cycle Lancelot-Graal, a fait preuve d'une extraordinaire vitalité. Reprise dans plusieurs textes médiévaux et sauvée plus tard par le revival de la matière arthurienne dans l'Angleterre victorienne, la dernière amoureuse de Lancelot réapparaît au cours du XXe siècle dans le cadre de romans anglophones, de pièces de théâtre et même sur le terrain des paralittératures. Bien que le poème « The Lady of Shalott » de Lord Alfred Tennyson ait été perçu comme une rupture dans cette tradition, la comparaison de ce poème avec sa source directe, la novella 82 de Cento Novelle Antiche, ainsi qu'avec le roman français permet de reconstruire une ligne thématique qui relie les trois textes.

The history of the demoiselle d'Escalot, minor character in La Mort le roi Artu, XIII century roman closing the Lancelot-Grail cycle, has demonstrated extraordinary vitality. Retold in several medieval texts and rescued later in the nineteenth century by the revival of Arthurian matter in Victorian England, the last Lancelot's lover reappears in the twentieth century in the framework of Anglophone novels, in plays and even on the grounds of the paralittératures. Although the poem "The Lady of Shalott" by Lord Alfred Tennyson has been seen as a break in that tradition, the comparison of that poem with its direct source, the novella 82 of Cento Novelle Antiche, and with the French roman allows to draw a thematic line relating the three texts between them.

\section{ÍNDICE}

Palabras claves: Demoiselle d'Escalot, Novellino, Shalott

Keywords: Demoiselle d'Escalot, Novellino, Shalott

Mots-clés: Demoiselle d'Escalot, Novellino, Shalott

\section{AUTOR}

\section{SUSANA G. ARTAL}

Facultad de Filosofía y Letras - Universidad de Buenos Aires sartal@filo.uba.ar 